\title{
Designing a Tangible Interface for Collaborative Storytelling to Access 'Embodiment' and Meaning Making
}

\author{
Cristina Sylla \\ engageLab/CIEd \\ University of Minho \\ Campus de Azurém \\ Guimarães, 4800-058, Portugal \\ sylla@engagelab.org
}

\begin{abstract}
This paper describes research on designing a tangible system for collaborative storytelling, which addresses preschool children. The first part of the work focused on creating a tangible interface, for children aged four to five years, proposing to create a playful experimental space where children can collaboratively engage in creating their own multimedia narratives. Further research proposes to carry a long term study with a group of 25 five preschoolers interacting with the developed tangible system, trying to investigate how physical interaction and collaboration might influence and shape cognitive and social processes in real classroom settings. We describe the design process, as well as the final system, and report findings from a first preliminary study.
\end{abstract}

\section{Categories and Subject Descriptors}

H.5 [Information interfaces and presentation] H.5.2 User interfaces: User-Centred Design.

\section{General Terms}

Design, Experimentation, Human Factors.

\section{Keywords}

Tangible Interfaces; Digital Manipulatives; Embodiment; Collaboration; Children; Storytelling; Participatory Design.

\section{INTRODUCTION}

Research on Tangible Interfaces has been addressing issues of embodiment and collaboration, considering that the very nature of tangible interfaces structures both the interaction and the social configurations [6]. Investigation on Embodied Cognition defends that the basis of all cognitive processes are our bodily experiences, and that even higher cognitive processes, ground on embodiment [8]. Recent approaches to Child Computer Interaction grounded on these theories stress the importance of the bodily experience and the strong connection between body and mind [1]. Tangible systems facilitate embodiment shaping both how users interact with the systems virtually and physically, promoting or hindering collaboration [6]. They have embodied constraints, which are inherent to the physical interaction space and the tangible tokens, multiple access points that allow for shared control, and tailored representations [6], which are

Copyright is held by the owner/ author(s).

IDC'13, June 24-27, 2013, New York, NY, United States.

ACM 978-1-4503-1918-8/13/06. understandable for the users, as they build on user's prior knowledge. In line with [6], Yuill and Rogers [13] identified three fundamental behavior mechanisms that underlie interactions of users doing collaborative tasks: mutual awareness of other users' actions, control (degree of each user's control over the actions), and availability (how relevant background information is accessible to all users). Price stresses the role of embodiment in shaping multimodal action flow, and the importance of body position, perspective, gaze and turn taking, investigating to what extent it influences the process of meaning making [11].

Given the central role of physicality in cognitive development tangible systems have been considered to be particularly suitable to be used by young children. Building up on these findings and proposing to further investigate the extent to which factors such as physical manipulation, the role of the body, and collaboration influence and shape meaning making processes, we developed a tangible system that may foster children's involvement in collaboratively creating their own narratives.

\section{CREATING NARRATIVES}

Storytelling and imaginative play often involve fancying story worlds where the most unexpected and incredible events might take place. Imaginative play is not only an activity that thrills children, it may as well play a key role in the development of high cognitive processes, such as thinking, reasoning, or learning [4]. Enrolling in imaginative play develops children's ability to think about alternative possibilities and work out their implications [5]. Collaboratively engaging in such activities provides opportunities for social interaction and the generation of new ideas, offering children a "nourishing habitat for the growth of cognitive, narrative and social connectivity" $[10$, p.8]. Starting from the concept of imaginative play we developed a tangible system for mediating children's multimedia narratives.

\section{PARTICIPATORY DESIGN}

The system was developed over a period of two years together with four groups of 25 children each, and 6 preschool teachers, following an iterative participatory design method. Although the teachers were always the same, we worked every year with two new groups of children, who were between four and five years old. From the two big groups we have split the children in smaller working groups. Besides working directly with the children during their classes, we also have the possibility of working with them in small groups without the teachers. This is particularly important to access information from the children avoiding any bias caused by the teachers. During these two years the initial concept underwent several changes always integrating the feedback from our children design partners [3]. Along this process we have designed and tested several low-fidelity prototypes in a cyclical process of creating, testing and 
redesigning. In the initial design phase we worked with very simple paper prototypes. Despite its simplicity these first prototypes enabled us to access important information on how to develop further. For instance, the paper prototypes on figure 1 represented the platform (green cardboard) and the picture cards represented the tangible tokens that children used to create narratives. The interaction with these paper prototypes showed us how children use picture cards for telling a story, how they place the cards on a "platform", which patterns they use for placing a card and tell the story. Additionally they let us envision the kind of social interactions that might emerge when the children collaboratively engage in creating stories with tangible tokens.

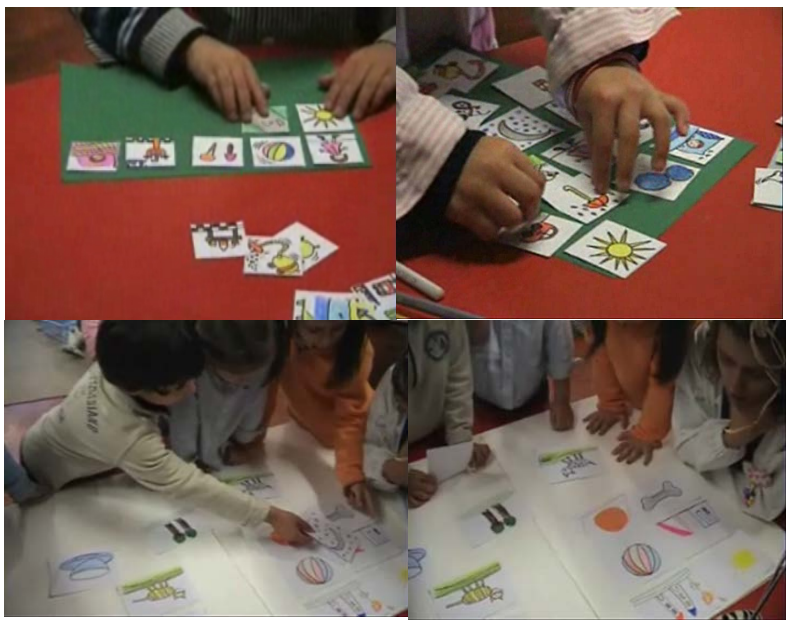

Figure 1. Different groups of children interacting with the first paper prototypes.

The results from these first studies revealed that the drawings on the cards inspired children's narratives. Children were very motivated to participate in each other's stories; they divided and shared the cards to create the narratives. The fact that children could handle the cards in their hands allowed for multiple control promoting reflection about the shared interaction. Sometimes, in key situations the children discussed with each other which card should be placed next. Other important information was children's mental and physical mapping of telling the story and placing the cards on the paper "platform". In respect to this the children used the space differently while verbalizing their stories. Some placed the cards on the top of the paper "platform" from left to right as if following an invisible line; others preferred to start by placing the cards on the bottom, and some did not follow any precise order, scattering the cards over the paper "platform", as if it was a drawing. However, most of the children tried to align the cards in rows. This showed us that it would be useful to have marks on the final system for placing the tangible tokens, and that the system should identify which card the user places and where s/he places it on the platform, and unfold the story according to that [12].

\section{THE FINAL SYSTEM}

Building on the idea of using tangible cards and a platform to collaboratively engage in storytelling we developed a tangible system, which is composed by different sets of picture-blocks, and an electronic platform that connects to a computer (fig. 2). The electronic platform has marks printed on it for indicating where to place the blocks. To create a narrative users place the blocks on the platform; each block triggers and displays an animation on the screen, according to the drawing on its surface. Presently the system recognizes up to 250 different blocks.

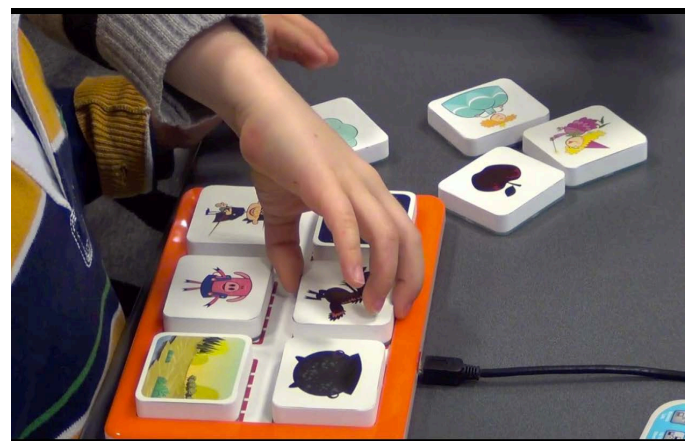

Figure 2. The tangible system

To create a story children can choose among four different sets of picture-blocks: sceneries, characters, objects and nature elements. Different sceneries, such as a castle landscape, a forest, a desert, or a circus allow locating the stories in different settings (fig. 3). The characters, which were inspired by familiar fairy tales and storybooks, comprise among others a dwarf, a fairy, a princess, a witch, three pigs and a wolf. The objects, such as a caldron, an apple, a carrot or a flowerpot can be used to influence the story plot; for instance children can use the caldron to knock down a character by letting it fall over him. The nature elements, as for instance a cloud can be used to blow away enemies. Children can mix and remix the characters, as they like, their familiarity allows children both to recreate familiar narratives, but also to create variations from the original stories, or different ones.
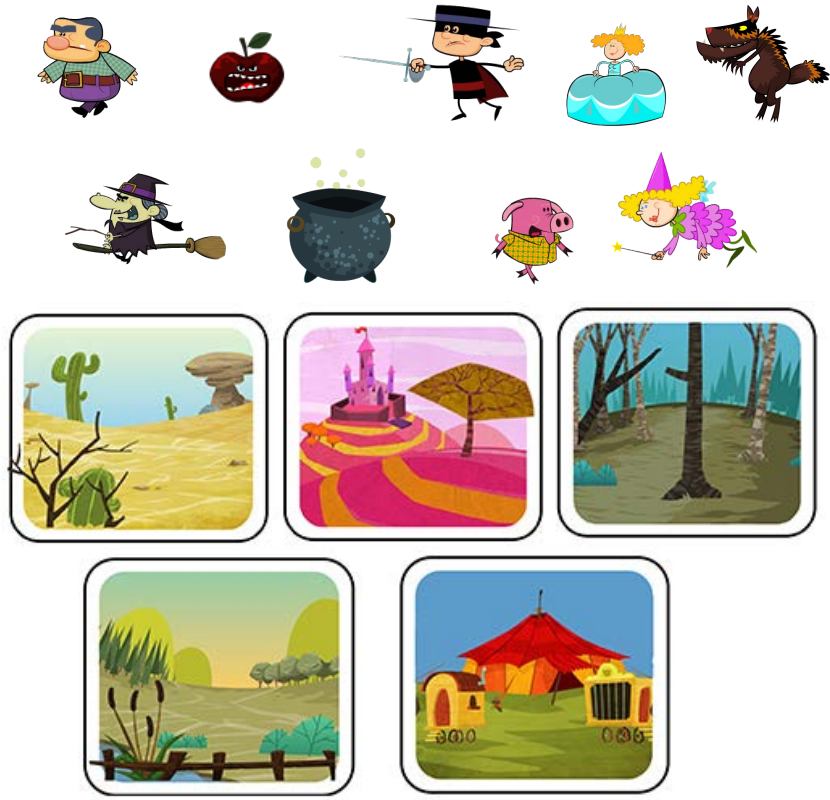

Figure 3. Examples of characters, objects and settings.

The story is generated by a storytelling engine, which animates the plot from the story elements selected by the users. Typically there are two different approaches to storytelling, plot-based or character-based. Plot-based approaches rely on pre-authored plot elements, which are combined, based on user interactions, thus providing direct reactions to user choices. Character-based approaches, on the other hand, target to generate stories based on the simulated behavior derived from parameter sets of the characters, and ontological world descriptions. Our model 
integrates plot- and character-based approaches, since we provide elements of both, general story elements describing tale-related courses, as well as specific character-based behaviors. This approach allows children to develop a wide variety of narratives, as there are no predefined stories, nor a linear narrative. Users create their own narratives according to the sequence of blocks that they use and the order in which they place them on the platform. Following the concept of a comic book, snapshots of the created narratives, which are shot within a certain time-lapse, can be uploaded to a blog or printed and shared with family and friends (fig.4). Children can as well use that as a support to show and tell their narratives to others.
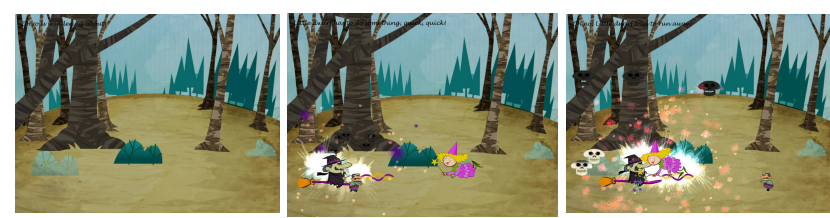

Figure 4. Some pictures from an uploaded story

\section{RELATED WORK}

There are various tangible systems that address storytelling targeting children between four to seven years old, such as the Siftables, PageCraft, or the Digital Dream Lab among others. Make a Riddle and TeleStory are educational applications developed on the Siftables platform. The Siftables [7] are hybrid tangible-graphical user interface devices, both Make a Riddle and TeleStory are language-learning applications for preschoolers. Make a Riddle teaches children spatial concepts and basic sentence-construction skills, TeleStory is designed to teach vocabulary and reading by enabling children to influence a story about a cat and a dog in a fanciful land. PageCraft [2] associates tangible props with text and visuals displayed on the screen, being able of tracking six characters and props. The Digital Dream Lab [9] is a tabletop puzzle block system intended for museum installation and designed to express abstract concepts such as containment, grouping and association to young children. Themes involve moving specific characters to specific locations to perform specific actions. Our system extends the possibilities from previous ones by providing a platform, which integrates plot - and character- based narratives, with no predefined stories, or linear narratives, enabling children to choose among a great range of story elements, empowering them to create their own original narratives. Additionally the uploaded narratives extend the user experience behind the interaction with the system, as they can be, printed, visualized and shared, as well as used as a support to show and tell friends and family.

\section{PRELIMINAR STUDIES}

We carried a preliminary study with a group of 14 children; we setup the system in the kindergarten's painting room, where just the children and the researcher were present. Two children at a time interacted with the interface. The researcher began by shortly introducing the system to the first group of children. The children began by exploring the blocks and the interactions between them, deeply involving in free exploration. When the second group of children came in after roughly 30 minutes, the children on the platform introduced the system to the newcomers, with no help from the researcher. Peer tutoring was highly efficient, engaging both the tutors and the tutees with the interface. By doing that the children acquired a sense of ownership regarding the system, which may result in cognitive and emotional involvement. The interface revealed to be very robust and entirely perceptive, the children immediately understood its functioning and how to place the blocks on the platform. After creating their stories the children still wanted to stay in the room, engaging in drawing at a table nearby. However, from time to time they would stop drawing curious about the stories that the other children were telling -, joining the ones on the platform, and collaborating all together in the narrative (fig. 5). This generated a constant dynamic between the children who were creating their stories and the other children in the room. Yuill and Rogers found out that the effects that tangible tokens produce seem to highly engage children in producing more creative stories and more social play [13]. During the interaction we observed following behaviors:

- Children scaffold each other explaining certain actions of certain story elements, which they had noticed during the interaction (e.g., the moon would turn the day into night).

- They discussed possible solutions to solve some situations, and reflected together over them considering different possibilities (e.g., how could they help the little pig to escape from the witch?).

- Children invited peers to collaborate with them to create a story together, saying it would be "more fun".

- They negotiated and divided the blocks among them to create a story together.

- Some children learned new vocabulary that was used by other children.

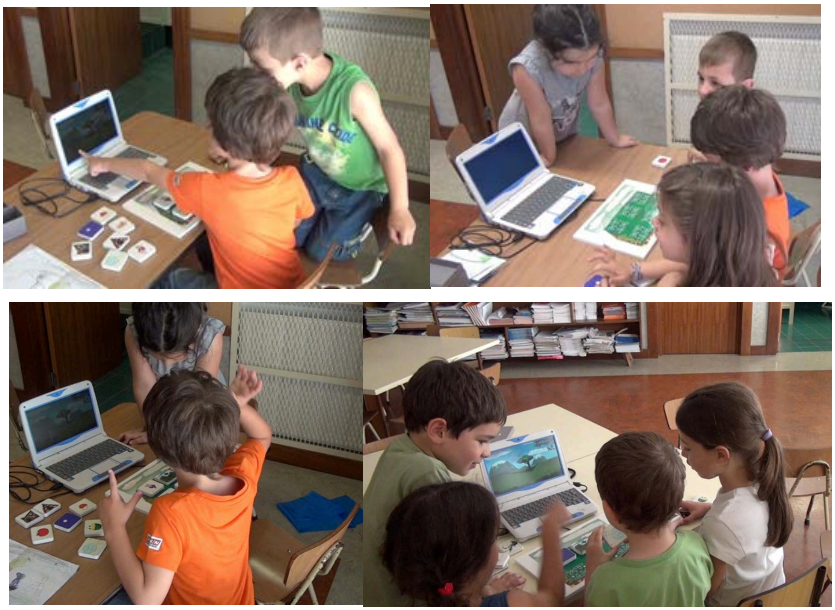

Figure 5. Children interacting with the final system

Having the possibility of collaboratively manipulating the digital content through tangible tokens the children emerged in the story world expressing their emotions not only through verbalizations e.g., addressing the characters with direct speech - but also through their body. They physically vibrated with the story at certain key moments, clapping their hands with joy when they achieved a certain goal, or when they were surprised by some unexpected reaction. They also grabbed their heads, wagged the arms over the head, shaking hands. Some children rose from their chairs excitedly, sometimes they tapped their foot impatiently.

\section{DISCUSSION}

One of the big challenges when carrying studies with children is to provide them a pleasant interaction experience; in many cases tangible interfaces prototypes are not able to endorse a smooth and pleasant experience often due to lack of robustness. Our system has proven extremely resilient, having overcome being manipulated by a group of preschool children without any 
restrictions. The study revealed that one of the strongest affordances of the platform is the extent to which it promoted collaboration, showing that the children were highly motivated to engage and collaborate in each other's stories. Various reasons may account for the collaboration:

- Children stood all on the same side, facing the platform, thus all having access both to the tangible tokens, the platform and the screen. They all had similar eye-view, which allowed straightforward communication and participation. Price and Jewitt suggest that body position, gaze, manipulation and speech are factors that shape interaction and meaning making [11].

- Multiple access points, control was unconstrained and distributed among the users $[6,13]$. Access to the tangible tokens changed constantly, as the children grabbed the blocks and placed them back scattered over the table, always on a new place. Restrictions to individual access were compensated by a constant change of the blocks' position on the table as children recurrently reached for them; placing them on their side each time they used a block. Some children also reached over their mates to grab the blocks they wanted. In some situations the children handled and divided the blocks among them, based on the elements they wanted to have. Hence we can conclude that somehow the children planned their narratives in advance.

- In terms of awareness, children could easily perceive the focus of their peers' attention through eye gaze and body posture $[11,13]$. Being aware of the effects triggered by the tangible tokens when used by other children seems to have captured children's interest engaging them to produce more creative stories and more social play [13].

- Shared knowledge over the content of the stories allowed children both to recreate well known narratives and to explore new story plots $[6,10,13]$

\section{CONCLUSIONS}

The results from this first study are very promising revealing that mechanisms such as mutual awareness of each others' interactions, control over interactions, availability of background information, and shared cultural knowledge are important factors that shape cognitive processes and social interaction. The second part of this work proposes to carry a long term study with a group of 25 preschoolers - four and five years old - interacting with the platform, to further deepen these issues, trying to access information about different collaboration patterns, and how physical interaction and collaboration might influence and shape cognitive and social processes in real classroom settings.

\section{ACKNOWLEDGMENTS}

I would like to thank my supervisors Prof. Pedro Branco and Prof. Clara Coutinho, as well as our team; Colégio Teresiano - Braga, the preschool children and the teachers. This work is funded by FEDER through the Operational Competitiveness Factors Program - COMPETE and by National Funds through the FCT Portuguese Foundation for the Science and the Technology within the Project: PTDC/CPE-CED/110417/2009, and the Doctoral Grant: SFRH / BD / 62531 / 2009.

\section{REFERENCES}

[1] Antle, A.N. 2013. Research opportunities: Embodied childcomputer interaction. I. J. of Child-Comput. Interact. 1,1 (Jan. 2013), 30-36. DOI= http://dx.doi.org/10.1016/j.ijcci.2012.08.001.
[2] Budd, J., Madej, K., Stephens-wells, J., De Jong, J., Katzur, E., Mulligan, L. 2007. PageCraft: learning in context a tangible interactive storytelling platform to support early narrative development for young children. In Proceedings of the 6th International Conference on Interaction Design and Children (Aalborg, Denmark, June 06-09, 2007), IDC'07. ACM, New York, NY, 97-100. DOI= doi $>\underline{10.1145 / 1297277.1297296}$

[3] Druin, A. 2002. The Role of Children in the Design of New Technology, BIT, Behav. Inform. Technol. 21,1, 1-25.

[4] Eagle, S. 2012. Learning in the early years: Social interactions around picture books, puzzles and digital technologies. Comput. \& Educ. 59, 1 (Aug. 2012), 38-49. $\mathrm{DOI}=\underline{10.1016 / \mathrm{j} . \text { compedu.2011.10.013 }}$

[5] Harris, P. L. 2000. The work of the imagination. Oxford, Blackwell.

[6] Hornecker, E. A Design Theme for Tangible Interaction: Embodied Facilitation. 2005. H. Gellersen et al. (eds.). In Proceedings of the 9th European Conference on ComputerSupported Cooperative Work, (Paris, France, September 1822, 2005), ECSCW 2005. Springer, 23-43.

[7] Hunter, S., Kalanithi, J., Merrill, D. 2010. Make a Riddle and TeleStory: Designing Children's Applications for the Siftables Platform. In Proceedings of the 9th International Conference on Interaction Design and Children (Barcelona, Spain, June 09-11, 2010), IDC'10. ACM, New York, NY, 206-209.

[8] Johnson M. 1987. The Body in the Mind, The Bodily Bases of Meaning, Imagination, and Reason. The University of Chicago Press, Chicago and London.

[9] Oh, H., Deshmane, A., Feiran, L., Yeon Han, J., Stewart, M., Tsai, M., Xu, X., Oakley, I. 2013. The Digital Dream Lab: Tabletop Puzzle Blocks for Exploring Programmatic Concepts. In Proceedings of the 7th International Conference on Tangible Embedded and Embodied Interaction (Barcelona, Spain, February 09-13, 2013), TEI'13. ACM, New York, NY, 51-56. DOI= doi $>10.1145 / 2460625.2460633$

[10] Paley, V.G.A. 2004. Child's Work: The Importance of Fantasy Play. Chicago University Press, Chicago.

[11] Price, S., Jewitt, C. 2013. A multimodal approach to examining 'embodiment' in tangible learning environments. In Proceedings the 7th International Conference on Tangible Embedded and Embodied Interaction (Barcelona, Spain, February 09-13, 2013), TEI'13. ACM, New York, NY, 4350. DOI $=$ doi $>10.1145 / 2460625.2460632$.

[12] Sylla, C., Branco, P., Coutinho, C., Coquet, M.E., Škaroupka D. 2011. TOK - a Tangible Interface for Storytelling. In Proceedings of the SIGCHI Conference on Human Factors in Computing Systems (Vancouver, BC, Canada, May 07-12, 2011), CHI '11. ACM, New York, NY, 1363-1368. DOI= doi $>\underline{10.1145 / 1979742.1979775}$

[13] Yuill, N., Rogers, Y. 2012. Mechanisms for Collaboration: A Design and Evaluation Framework for Multi-User Interfaces. In Proceedings of ACM Transactions on Computer-Human Interaction TOCHI 2012. 19, 1, (Mar. 2012). 